\title{
Influence of Ti and REE on Primary Crystallization and Wear Resistance of Chromium Cast Iron
}

\author{
Malwina Dojka, Rafał Dojka, Marcin Stawarz, and Andrzej Studnicki
}

\author{
(Submitted September 27, 2018; in revised form April 8, 2019; published online May 16, 2019)
}

\begin{abstract}
The article presents the results of primary crystallization, wear resistance and SEM studies of chromium cast iron inoculated with ferrotitanium and rare earth elements as a mischmetal inoculating mixture. Thermal-derivative analysis method was used to conduct studies of primary crystallization in two types of testers, namely ATD-C and ATD-Is, reflecting two different cooling speeds. Wear resistance tests were performed with the use of modified pin-on-disk method on Tribotester 3-POD device, where the samples were moving in circular motion in metal-mineral friction system. Silicon carbide was used as a counter sample. The studies allowed to determine the influence of selected inoculants on the microstructure and wear resistance of the studied samples. All characteristic crystallization temperatures of samples casted into ATD-Is testers increased, as well as wear resistance of each inoculated samples compared to the noninoculated sample. It was proven that $\mathrm{TiC}$ and $\mathrm{REE}$ compounds are effective inoculants for chromium carbides and that REE compounds can work as underlay for TiC crystallization.
\end{abstract}

Keywords chromium cast iron, inoculation, mischmetal, titanium, wear

\section{Introduction}

Castings made of chromium cast iron are generally working in hostile conditions, where intense wear is the main problem. In industries such as mining, mineral processing or energetics, chromium cast iron is commonly used for elements exposed to increased wear. Ball and ring mill parts, rollers, transporting elements, abrasion shields, excavator teeth, etc., are parts, whose working conditions are very hard, and for this reason, in order to avoid frequent replacements of those parts, selection of proper material is vital to achieve the longest possible life span of the casting $(\operatorname{Ref} 1,2)$. There are many materials that have better wear resistance than chromium cast iron, but their price is much higher. One of the reasons why chromium cast iron is such an attractive material is its excellent ration between wear resistance and production cost.

But what if wear resistance of selected chromium cast iron is insufficient for our needs? One of the possibilities is to use alloying elements different than chromium, which will form different carbides, resulting in enhancement of wear resistance, but such action will highly increase the cost of production.

This article is an invited submission to JMEP selected from presentations at the 73rd World Foundry Congress and has been expanded from the original presentation. 73WFC was held in Krakow, Poland, September 23-27, 2018, and was organized by the World Foundry Organization and Polish Foundrymen's Association.

Malwina Dojka, Rafal Dojka, Marcin Stawarz, and Andrzej Studnicki, Department of Foundry Engineering, Silesian University of Technology, Towarowa 7, 44-100 Gliwice, Poland. Contact e-mails: malwina.dojka@polsl.pl, rafal.dojka@polsl.pl, marcin.stawarz@polsl.pl, andrzej.studnicki@polsl.pl
However, if the amount of the element would be small enough, we would deal with inoculation rather than with alloying, while the cost would stay comparatively low and wear resistance would increase.

Inoculation is the perfect way to change the kinetics of the crystallization process in a way to affect formation of microstructure and characteristic crystallization temperatures, which will result in improvement of casting properties.

Usually, a fraction of percent of weight is enough to clearly see inoculants' effect on the microstructure. However, higher amounts of inoculants were used in this work to not only ensure refinement of grain, but also provide significant increase in the wear resistance.

Studies concentrated on heterogeneous inoculation with ferrotitanium (FeTi67) and mischmetal consisting mainly of Ce and $\mathrm{La}(67 \% \mathrm{Ce}$ and $33 \% \mathrm{La})$. In order to create underlay which can increase the rate of crystallization, the mismatch $\delta$ between lattice parameters of the underlay and inoculated phase should be as low as possible. It was determined that inoculation is most effective when $\delta<6 \%$, its effectiveness is moderate between 6 and $12 \%$, and it is ineffective if $\delta>12 \%$.

$\mathrm{Ma}$ et al. calculated the lattice parameters of $\mathrm{Cr}_{7} \mathrm{C}_{3}$ carbides present in examined high chromium cast irons and obtained the following results: $a=b=6.88 \AA ; c=4.54 \AA$ in a hexagonal system, as well as $a=b=c=4.32 \AA(\delta=4.8)$ in case of TiC carbides in a regular system. Also, TiC has high melting point allowing its formation before the crystallization of $\mathrm{Cr}_{7} \mathrm{C}_{3}$, as well as hardness of up to 9.5 in Mohs' scale, which could influence the wear resistance of the final alloy (Ref 3-5).

According to calculations of $\mathrm{Qu}$ et al. (Ref 6), lattice parameters of $\mathrm{Cr}_{7} \mathrm{C}_{3}$ carbides are $a=b=6.99 \AA ; c=4.036 \AA$, and the parameters of $\mathrm{Ce}_{2} \mathrm{O}_{2} \mathrm{~S}$, are $a=b=6.942 ; c=4.036 \mathrm{~A}$ $(\delta=0.69)$ in a hexagonal system. These studies proved that both $\mathrm{TiC}$ and $\mathrm{Ce}_{2} \mathrm{O}_{2} \mathrm{~S}$ are effective inoculants of $\mathrm{Cr}_{7} \mathrm{C}_{3}$ carbides.

It is a fact that both mischmetal and ferrotitanium are often used as inoculants for $\mathrm{Cr}_{7} \mathrm{C}_{3}$ carbides (Ref 7-14). However, usually one is used without the presence of the other. In this 
work, both inoculants were simultaneously added to the melt in order to evaluate their synergistic effect.

\section{Materials and Methodology of the Studies}

The initial W0 melt was eutectic chromium cast iron melted using electric induction furnace with the capacity of $50 \mathrm{~kg}$, including corundum lining. Charge consisted of materials commonly used in industrial conditions: steel scrap, ferrochromium and carburizer. Inoculated melts were made in electric induction furnace with the capacity of $20 \mathrm{~kg}$ with corundum lining by re-melting W0 melt and adding an inoculant into the ladle. In case of TiMM004 sample, the following amount of inoculants was added: mischmetal $-0.06 \%$ by weight of the charge, titanium- $-0.06 \%$ by weight of the charge, while in case of TiMM1 the amount was: mischmetal $-2 \%$ by weight of the charge, titanium $-2 \%$ by weight of the charge. Table 1 presents chemical compositions of obtained melts prepared using LECO spectrometer.

Thermal-derivative analysis method (TDA) can be used to present the entire crystallization process. In this case, it was used to examine the kinetics of the primary crystallization. Figure 1 shows used test stand, consisting of a computer linked to CRYSTALDIGRAPH device connected to two testers reflecting two different cooling speeds in order to examine crystallization with two different solidification times: ATD-C with shorter solidification time (W0, TiMM004, TiMM1) and ATD-Is with longer solidification time (W0i, TiMM004i,

Table 1 Chemical composition of examined high chromium cast iron

\begin{tabular}{lccc}
\hline & \multicolumn{3}{c}{ Sample } \\
\cline { 2 - 4 } Element, \% & Wo & TiMM004 & TiMM1 \\
\hline $\mathrm{C}$ & 3.06 & 2.96 & 3.23 \\
$\mathrm{Mn}$ & 0.65 & 0.596 & 0.549 \\
$\mathrm{Si}$ & 0.386 & 0.434 & 0.667 \\
$\mathrm{P}$ & 0.019 & 0.020 & 0.022 \\
$\mathrm{~S}$ & 0.023 & 0.019 & 0.032 \\
$\mathrm{Cr}$ & 19.3 & 19.0 & 19.1 \\
$\mathrm{Ni}$ & 0.242 & 0.231 & 0.254 \\
$\mathrm{Mo}$ & 0.03 & 0.032 & 0.056 \\
$\mathrm{~V}$ & 0.158 & 0.170 & 0.190 \\
$\mathrm{Cu}$ & 0.124 & 0.128 & 0.128 \\
$\mathrm{Al}$ & 0.013 & 0.040 & 0.078 \\
$\mathrm{Ti}$ & 0.0 & 0.043 & 1.18 \\
\hline
\end{tabular}

TiMM1i). Solidification time of the melt in ATD-Is tester is approximately two times longer than in ATD-C tester.

Crystallization kinetics was measured with the use of CRYSTALDIGRAPH analyzer designed and manufactured in cooperation with the Department of Foundry Engineering of Silesian University of Technology. Type "S" (PtRh10-Pt) thermocouples were used. Application of TDA method allowed registration of cooling $(T=f(t))$ and crystallization $\left(T^{\prime}=\frac{\mathrm{d} T}{\mathrm{~d} t}\right)$ curves. Analysis of both curves was conducted according to theories of prof. Stanisław Jura (Ref 15-19), Polish authority in the field of crystallization examination. Analysis allowed authors to designate characteristic temperatures of examined melts crystallization. Methodology of temperature designation is schematically shown in Fig. 2 presenting crystallization curves of a) for eutectic alloy, b) and c) for near eutectic alloy. Figure 2(b) presents the variant in which crystallization curve reaches positive values which results in the presence of metastable crystallization temperature, and Fig. 2(c) shows the variant in which the derivative value is negative and only stable temperature is present. Description of each analyzed characteristic point is shown in Table 2 for eutectic alloy and Table 3 for near eutectic alloy.

Wear resistance tests based on modified pin-on-disk method were conducted with the use of Tribotester 3-POD device. In this method, the wear of the examined sample was compared to the wear of a wear test reference sample made of Creusabro 8000 (C8) wear resistant steel. Samples for wear resistance tests were extracted from overflow parts of TDA testers. Dry wear tests were done using $\mathrm{C} 120 \mathrm{SiC}$ abrasive paper with a disk rotational speed of $155 \mathrm{rpm}$, a sample holder speed of $400 \mathrm{rpm}$, a load of $220 \mathrm{~g}$ and test cycle time of $10 \mathrm{~min}$ for six cycles.

\section{Results and Discussion}

\subsection{Crystallization Analysis}

Figure 3 shows cooling and crystallization curves of W0 melt, and Table 4 presents characteristic temperatures and points of crystallization process. It should be noticed that melt W0 in both tester variants crystallized as a eutectic alloy. In both testers, crystallization started with metastable liquidus temperature, which means that supercooling was necessary to initiate the crystallization process. In case of ATD-C tester, eutectic recalescence, expressed as the difference between $T_{\mathrm{S}}$ and $T_{\mathrm{SM}}(\operatorname{Ref} 20,21)$, was $\Delta R_{\mathrm{C}}=2.4{ }^{\circ} \mathrm{C}$, and in case of ATDIs tester $-\Delta R_{\mathrm{Is}}=3.8^{\circ} \mathrm{C}$. Occurrence of metastable crystallization temperature is typical for non-inoculated alloys.

Figure 4 presents cooling and crystallization curves of TiMM004 melt, while Table 5 shows characteristic tempera-

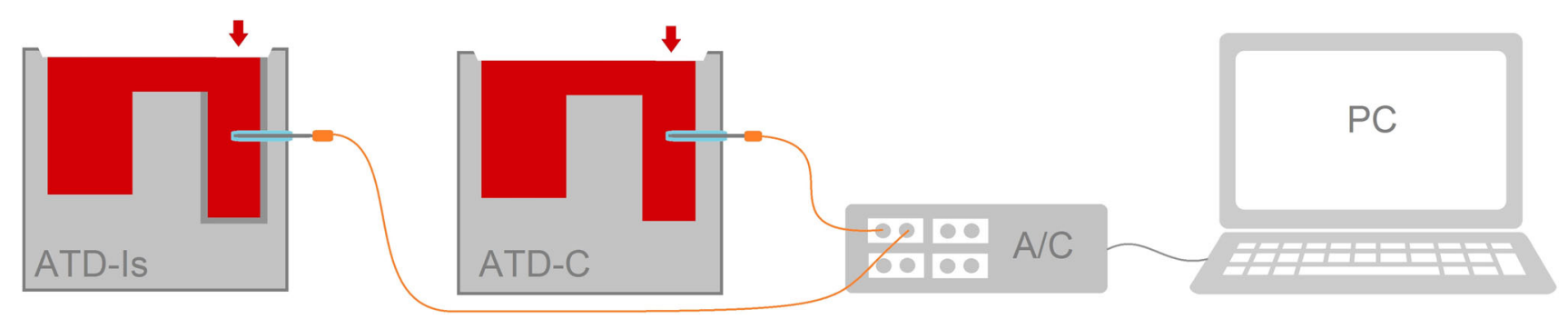

Fig. 1 Scheme of the test stand (Ref 1) 


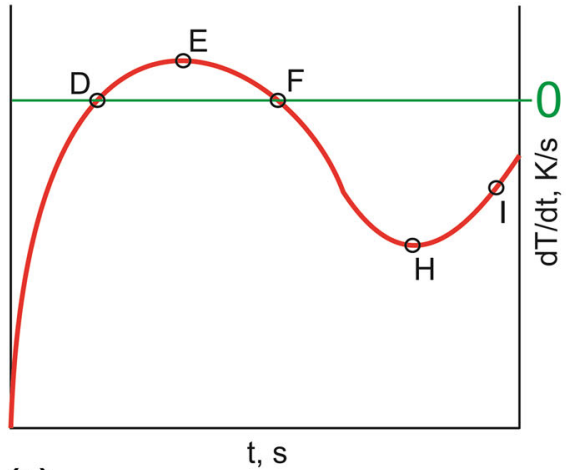

(a)

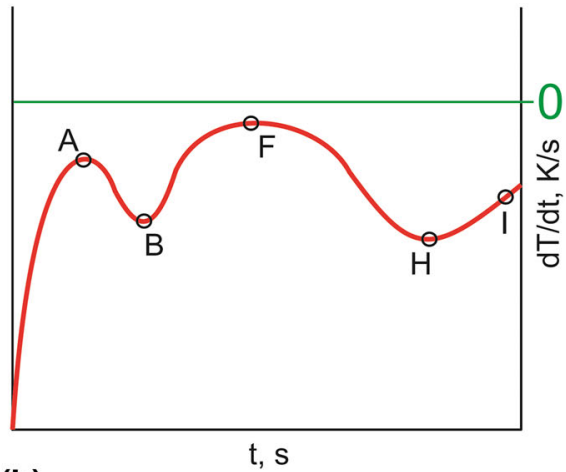

(b)

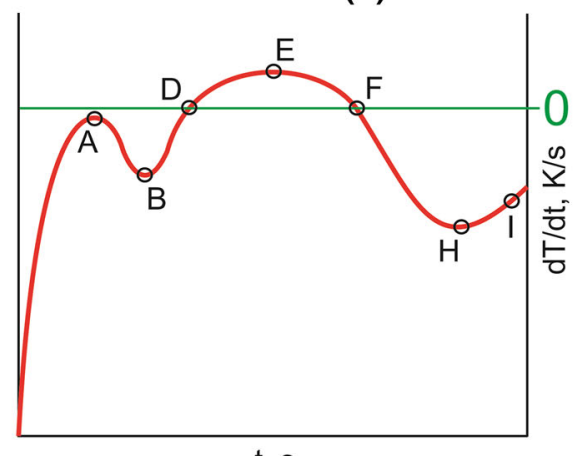

(c)

$\mathrm{t}, \mathrm{s}$

Fig. 2 Methodology of characteristic temperatures designation for (a) eutectic alloy, (b) and (c) near eutectic alloy

Table 2 Description of each analyzed characteristic point of TDA for eutectic alloy

\begin{tabular}{lll}
\hline Point & Temperature & \multicolumn{1}{c}{ Description } \\
\hline $\mathrm{Z}$ & $T_{\mathrm{Z}}$ & Pouring temperature and maximal registered temperature \\
$\mathrm{D}$ & $T_{\mathrm{LM}}=T_{\mathrm{SM}}$ & Liquidus and solidus temperature of metastable eutectic phase crystallization \\
$\mathrm{E}$ & $T_{\mathrm{E}}$ & Maximal heat effect of eutectic phase crystallization and maximal heating intensity \\
$\mathrm{F}$ & $T_{\mathrm{S}}$ & Solidus temperature of stable eutectic phase crystallization \\
$\mathrm{H}$ & $T_{\mathrm{H}}$ & End of crystallization \\
$\mathrm{I}$ & $T_{\mathrm{I}}$ & Characteristic temperature in solid state $\left(1050{ }^{\circ} \mathrm{C}\right)$ \\
\hline
\end{tabular}

Table 3 Description of each analyzed characteristic point of TDA for near eutectic alloy

\begin{tabular}{lll}
\hline Point & Temperature & Description \\
\hline $\mathrm{Z}$ & $T_{\mathrm{Z}}$ & $\begin{array}{l}\text { Pouring temperature and maximal registered temperature } \\
\text { A }\end{array}$ \\
& $T_{\mathrm{L}}$ & $\begin{array}{c}\text { Liquidus temperature, for hypoeutectic alloys, it reflects maximum heat effect } \\
\text { of phase } \gamma \text { dendrites crystallization, and for hypereutectic alloys, it reflects maximum } \\
\text { heat effect of primary carbide } \mathrm{M} \text { C3 phase crystallization }\end{array}$ \\
$\mathrm{B}$ & $T_{\mathrm{B}}$ & Maximal intensity of cooling after maximum heat effect of primary phase crystallization \\
$\mathrm{D}$ & $T_{\mathrm{SM}}$ & Solidus temperature of metastable eutectic phase crystallization \\
$\mathrm{E}$ & $T_{\mathrm{E}}$ & Maximal heat effect of eutectic phase crystallization and maximal heating intensity \\
$\mathrm{H}$ & $T_{\mathrm{S}}$ & Solidus temperature of stable eutectic phase crystallization \\
$\mathrm{I}$ & $T_{\mathrm{H}}$ & End of crystallization \\
\hline
\end{tabular}

tures and melting points of the crystallization process, which was typical for near eutectic alloy. In this case, there was no visible eutectic recalescence, which means that there was no metastable temperature of crystallization that could indicate ineffectiveness of inoculation. In both ATD-C and ATD-Is testers, the values of $T_{\mathrm{L}}, T_{\mathrm{S}}$ and $T_{\mathrm{H}}$ were higher compared to W0 melt, which showed higher crystallization start potential. There is a visible heat effect on the crystallization curve before point A depicting $T_{\mathrm{L}}$; this effect starts at temperature of $1310.4{ }^{\circ} \mathrm{C}$ and ends at $1287.1{ }^{\circ} \mathrm{C}$. In the authors' opinion, this 

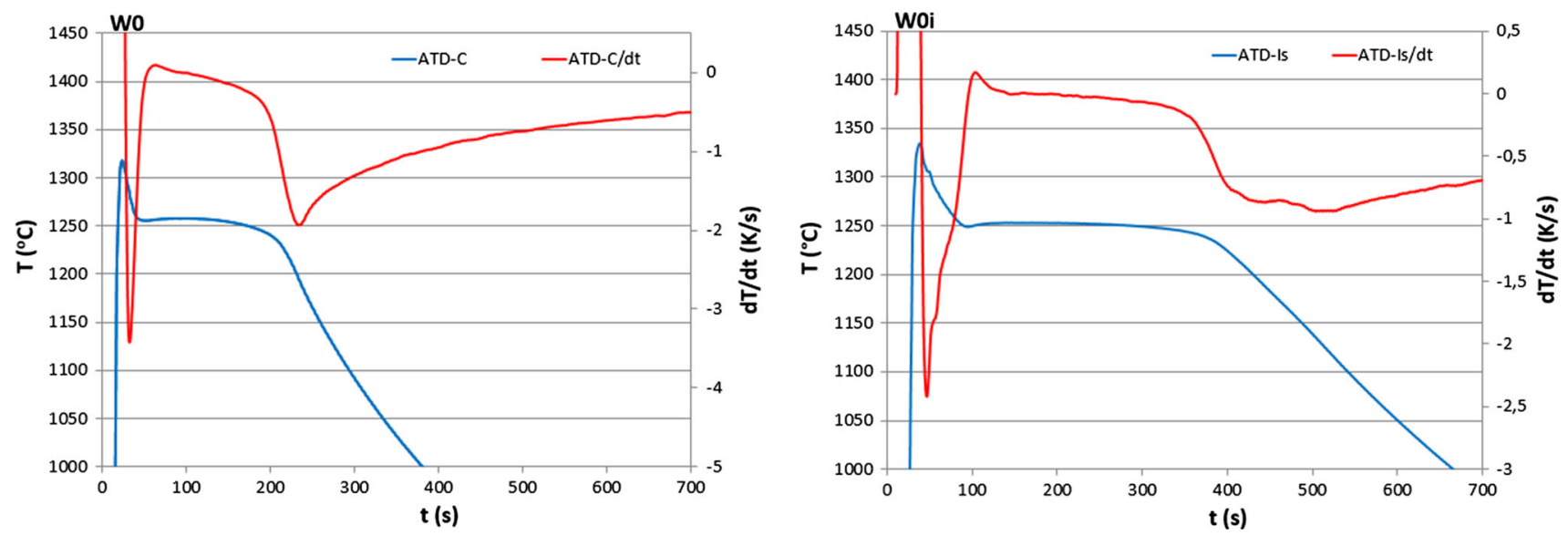

Fig. 3 TDA curves of W0 melt

Table 4 Characteristic temperatures of W0 and W0i samples

\begin{tabular}{|c|c|c|c|c|c|}
\hline \multirow[b]{2}{*}{ Point } & \multirow[b]{2}{*}{ Effect } & \multicolumn{2}{|c|}{ Wo sample } & \multicolumn{2}{|c|}{ W0i sample } \\
\hline & & $\boldsymbol{T},{ }^{\circ} \mathrm{C}$ & $\mathrm{d} T / \mathrm{d} t, \mathrm{~K} / \mathrm{s}$ & $T,{ }^{\circ} \mathbf{C}$ & $\mathrm{d} T / \mathrm{d} t, \mathrm{~K} / \mathrm{s}$ \\
\hline Z & $T_{\mathrm{Z}}$ & 1317.6 & 13.8312 & 1334.0 & 6.10299 \\
\hline $\mathrm{D}$ & $T_{\mathrm{L}}, T_{\mathrm{SM}}$ & 1255.5 & 0.1151 & 1248.8 & 0.00509 \\
\hline E & $T_{\mathrm{E}}$ & 1256.4 & 0.09421 & 1250.4 & 0.16884 \\
\hline $\mathrm{F}$ & $T_{\mathrm{S}}$ & 1257.5 & -0.00114 & 1252.6 & -0.00115 \\
\hline $\mathrm{H}$ & $T_{\mathrm{H}}$ & 1190.9 & -1.93208 & 1186.0 & -0.87057 \\
\hline I & $T_{\mathrm{I}}$ & 1049.8 & -1.15768 & 1049.7 & -0.81545 \\
\hline
\end{tabular}
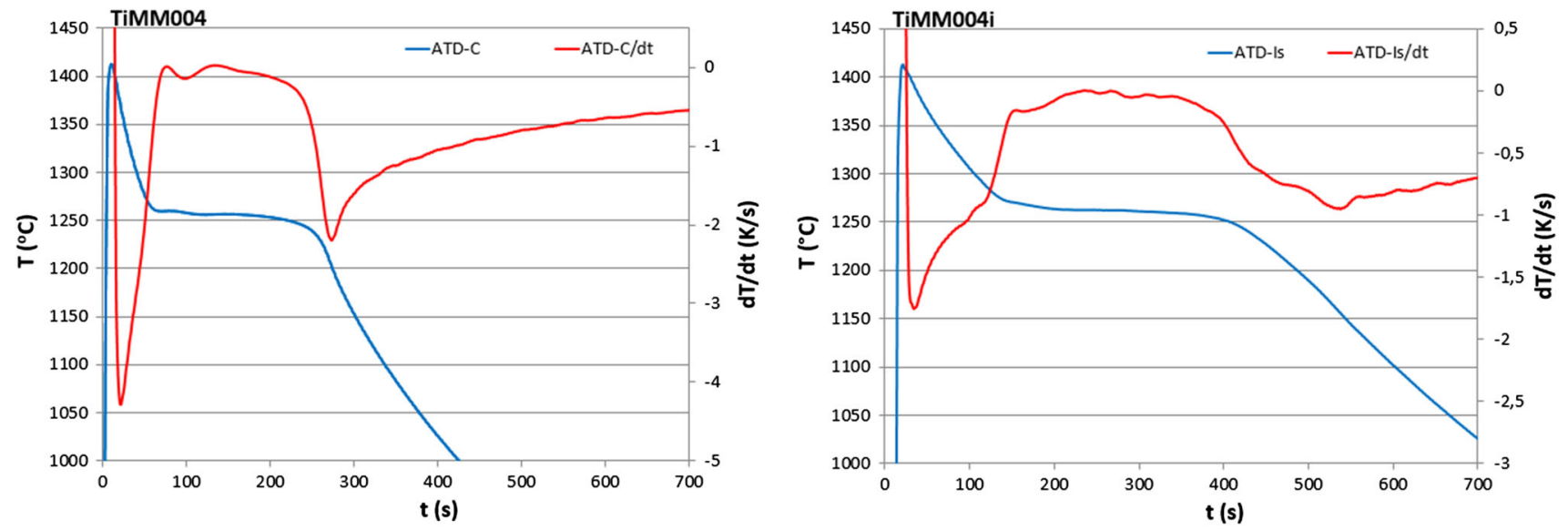

Fig. 4 TDA curves of TiMM004 melt

effect is caused by crystallization of $\mathrm{TiC}$ and $\mathrm{Ce}_{2} \mathrm{O}_{2} \mathrm{~S}$; however, this will be verified in further research.

Figure 5 presents cooling and crystallization curves of TiMM1 melt, and Table 6 shows characteristic temperatures and points of crystallization process, which, again, was typical for near eutectic alloy. Just like in the previously analyzed melt, in this case, there was no visible eutectic recalescence, which proves that inoculation was effective. In ATD-Is tester, $T_{\mathrm{L}}$ and $T_{\mathrm{H}}$ were higher compared to $\mathrm{W} 0$ melt, but $T_{\mathrm{S}}$ had decreased. In case of ATD-C tester, $T_{\mathrm{L}}, T_{\mathrm{S}}$ and $T_{\mathrm{H}}$ were lower than in W0 melt. This shows that inoculation took place, but the crystallization start potential was reduced.
As in the case of the previous melt, there was a heat effect prior to $T_{\mathrm{L}}$ between $1441.9{ }^{\circ} \mathrm{C}$ and $1287.1{ }^{\circ} \mathrm{C}$. Again, authors believe it is associated with precipitation of $\mathrm{TiC}$ and $\mathrm{Ce}_{2} \mathrm{O}_{2} \mathrm{~S}$.

It is important to emphasize the fact that the results obtained from isolated testers are closer to the conditions of equilibrium, because longer crystallization time facilitated diffusion of elements in liquid and solid state. Longer crystallization time also corresponds to the actual industrial conditions of high chromium cast iron crystallization to a greater extent, as castings made from this material are usually characterized by thick walls. 


\subsection{Metallographic Analysis}

Metallographic photography of W0 melt is shown in Fig. 6, where $\mathrm{Cr}_{7} \mathrm{C}_{3}$ carbides in matrix consisting of alloy pearlite and austenite are visible. Figure 7 shows metallographic photography of TiMM004 melt with $\mathrm{Cr}_{7} \mathrm{C}_{3}$ and $\mathrm{TiC}$ carbides in matrix consisting of alloy pearlite and austenite. Interesting change takes place in case of TiMM1 melt visible in Fig. 8, where $\mathrm{Cr}_{7} \mathrm{C}_{3}$ and $\mathrm{TiC}$ carbides are still present, but matrix consists of austenite. Such transition may be explained by slightly increased amount of $\mathrm{C}$ content in TiMM1 sample; however, the presence of $\mathrm{Ti}$ binding $\mathrm{C}$ in $\mathrm{TiC}$ moves the eutectic point. This change can also be linked with a phenomenon present in the third generation of AHSS steels, where grain refinement decreases starting temperature of martensitic transition, thus leaving the matrix austenitic in room temperature (Ref 22-24). The presence of austenitic matrix should highly increase the impact strength of the alloy, and for this reason, this change will be carefully analyzed in future studies.

Image analysis allowed to determine that in both inoculated samples, the average area of carbides and their average length have decreased, while the rounding coefficient has increased. In case of W0, the average area of carbide was $73.276 \mu \mathrm{m}^{2}$, the average length was $12.594 \mu \mathrm{m}$, and the rounding coefficient was 0.402 . In TiMM004 sample, the average area of carbide was $59.021 \mu \mathrm{m}^{2}$, the average length was $9.707 \mu \mathrm{m}$, and the rounding coefficient was 0.411 . Sample TiMM1 reached the average area of carbide of $50.919 \mu \mathrm{m}^{2}$, the average length of $9.889 \mu \mathrm{m}$, and the rounding coefficient was 0.452 . In case of each sample, the analysis was carried out on 20 microstructure photographs. Results prove that refinement of the structure took place, while

Table 5 Characteristic temperatures of TiMM004 and TiMM004i samples

\begin{tabular}{|c|c|c|c|c|c|}
\hline \multirow[b]{2}{*}{ Point } & \multirow[b]{2}{*}{ Effect } & \multicolumn{2}{|c|}{ TiMM004 sample } & \multicolumn{2}{|c|}{ TiMM004i sample } \\
\hline & & $T,{ }^{\circ} \mathrm{C}$ & $\mathrm{d} T / \mathrm{d} t, \mathrm{~K} / \mathrm{s}$ & $T,{ }^{\circ} \mathrm{C}$ & $\mathrm{d} T / \mathrm{d} t, \mathrm{~K} / \mathrm{s}$ \\
\hline $\mathrm{Z}$ & $T_{\mathrm{Z}}$ & 1412.6 & 42.02624 & 1412.8 & 35.9199 \\
\hline A & $T_{\mathrm{L}}$ & 1259.8 & -0.00638 & 1269.6 & -0.02546 \\
\hline $\mathrm{B}$ & $T_{\mathrm{B}}$ & 1257.9 & -0.14235 & 1268.4 & -0.16731 \\
\hline $\mathrm{F}$ & $T_{\mathrm{S}}$ & 1256.5 & -0.00147 & 1262.4 & -0.00065 \\
\hline $\mathrm{H}$ & $T_{\mathrm{H}}$ & 1203.7 & -2.19835 & 1204.8 & -0.75891 \\
\hline I & $T_{\mathrm{I}}$ & 1049.6 & -1.14845 & 1050.3 & -0.75452 \\
\hline
\end{tabular}

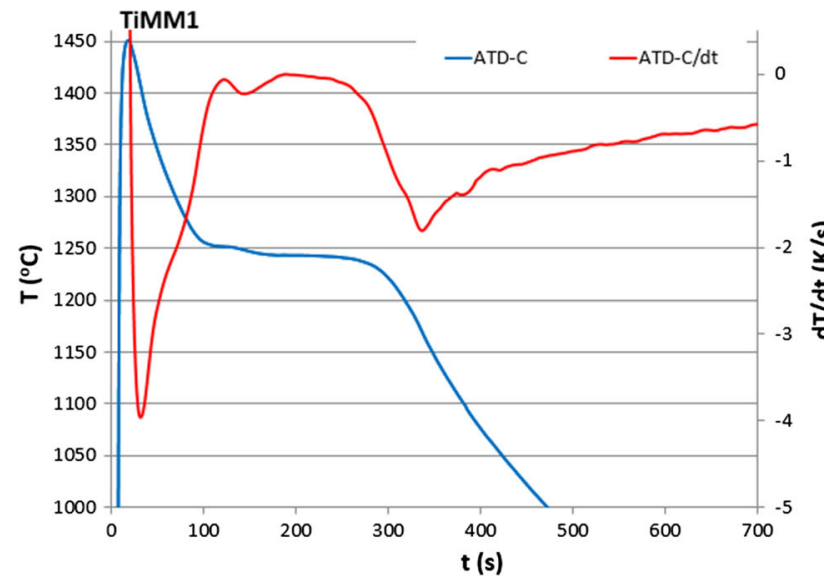

Fig. 5 TDA curves of TiMM1 melt carbides in inoculated samples are rounded, as opposed to noninoculated samples, so their impact strength should be greater. In case of TiMM004, the average carbide area was $19 \%$ lower, the length was $23 \%$ lower, and rounding was $2 \%$ larger than in W0 sample. In TiMM1 sample, the average carbide area was $30 \%$ lower, the length was $21 \%$ lower, and rounding was $9 \%$ larger. The results indicate that mixture of $\mathrm{Ti}$ and $\mathrm{REE}$ has a positive impact on the microstructure of the alloy as significant refinement of microstructure was achieved.

Addition of larger amount of Ti resulted in formation of TiC conglomerate, as its distribution in the matrix was far from uniform. This phenomenon is perfectly visible in Fig. 12. Titanium carbides formed in the melt may present a tendency to move upward, toward the surface. This effect can be a result of density difference between molten metal $\left(6.6-7.1 \mathrm{~g} / \mathrm{cm}^{3}\right)$ and $\mathrm{TiC}\left(4.91 \mathrm{~g} / \mathrm{cm}^{3}\right)$ as well as with convection movements. In case of $\mathrm{Cr}_{7} \mathrm{C}_{3}$, the density difference is lower, as their density $\left(6.68 \mathrm{~g} / \mathrm{cm}^{3}\right)$ is very similar to the liquid metals density and no chromium carbide conglomerates were present. Formation of conglomerates can be caused by entrapment and entanglement of emerging titanium carbides into oxide bifilms formed during turbulent mold filling which is consistent with prof. John Campbells theories (Ref 25). This mechanism of conglomerate formation can be supported by authors' unpublished studies confirming segregation of $\mathrm{TiC}$ on the castings height.

\subsection{Wear Analysis}

Figure 9 presents diagram of weight loss of the examined chromium cast iron samples during wear resistance test measurement cycles. Figure 10 presents relative weight loss

Table 6 Characteristic temperatures of TiMM1 and TiMM1i samples

\begin{tabular}{lcccccc}
\hline & & \multicolumn{2}{c}{ TiMM1 sample } & & \multicolumn{2}{c}{ TiMM1i sample } \\
\cline { 7 - 7 } Point & Effect & $T,{ }^{\circ} \mathbf{C}$ & $\mathbf{d} \boldsymbol{T} / \mathbf{d} \boldsymbol{t}, \mathbf{K} / \mathbf{s}$ & & $\boldsymbol{T},{ }^{\circ} \mathbf{C}$ & $\mathbf{d} \boldsymbol{T} / \mathbf{d} \boldsymbol{t}, \mathbf{K} / \mathbf{s}$ \\
\hline $\mathrm{Z}$ & $T_{\mathrm{Z}}$ & 1450.7 & 6.498642 & & 1497.5 & 1.318549 \\
$\mathrm{~A}$ & $T_{\mathrm{L}}$ & 1251.6 & -0.0619 & & 1261.1 & -0.8617 \\
$\mathrm{~B}$ & $T_{\mathrm{B}}$ & 1248.3 & -0.2267 & & 1255.1 & -0.19172 \\
$\mathrm{~F}$ & $T_{\mathrm{S}}$ & 1243.2 & -0.0019 & & 1251.6 & -0.00073 \\
$\mathrm{H}$ & $T_{\mathrm{H}}$ & 1170.8 & -1.8084 & & 1204.1 & -0.70745 \\
$\mathrm{I}$ & $T_{\mathrm{I}}$ & 1049.5 & -1.09693 & & 1049.9 & -0.7968 \\
\hline
\end{tabular}

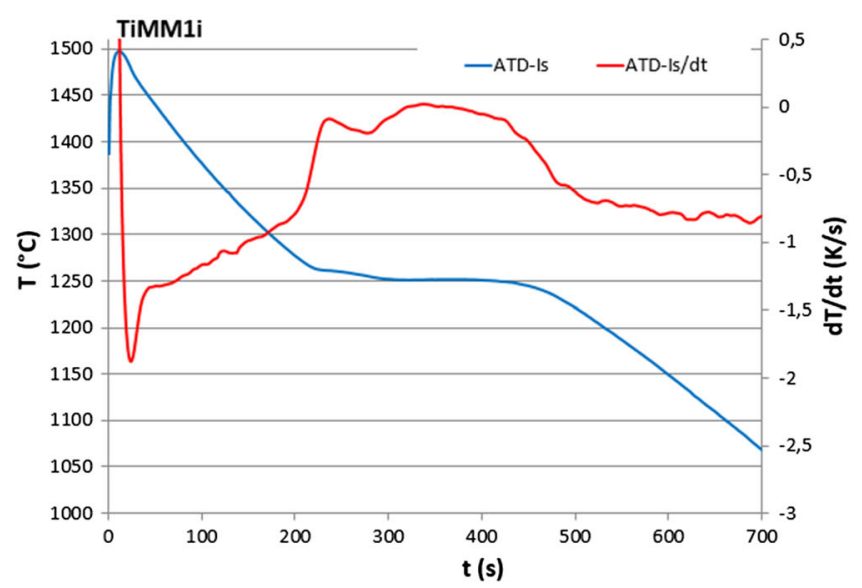



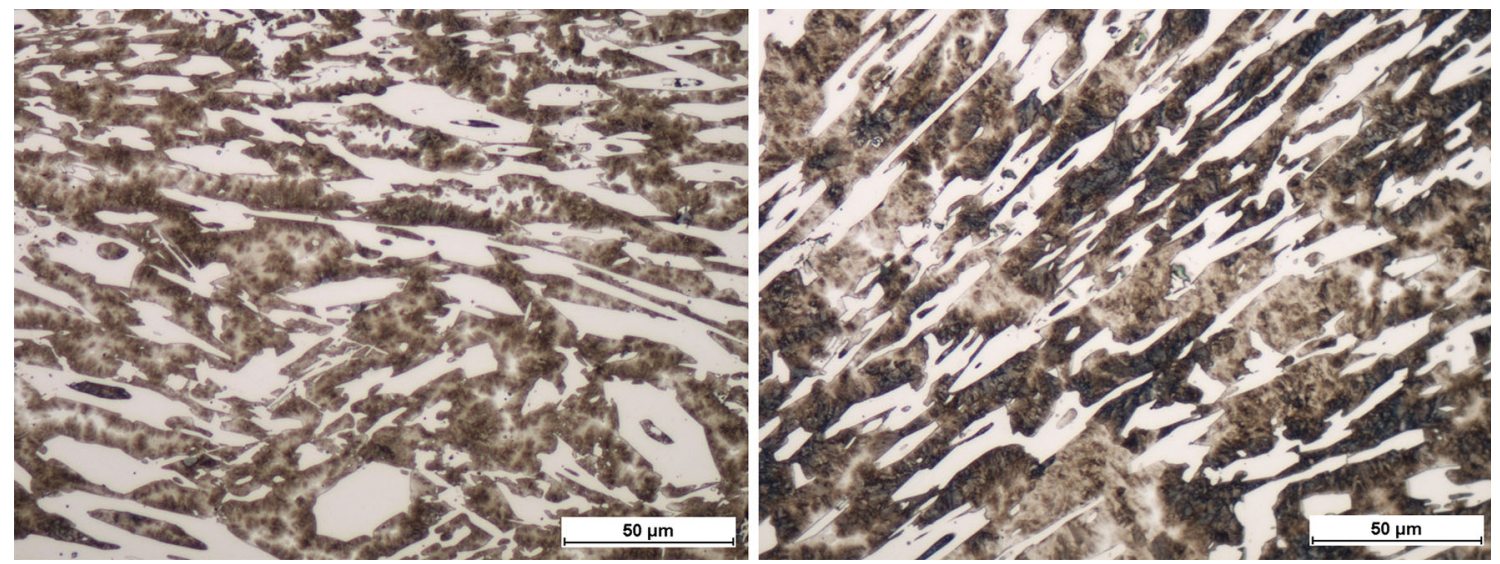

Fig. 6 Microstructure of W0 sample, on the left ATD-C, on the right ATD-Is
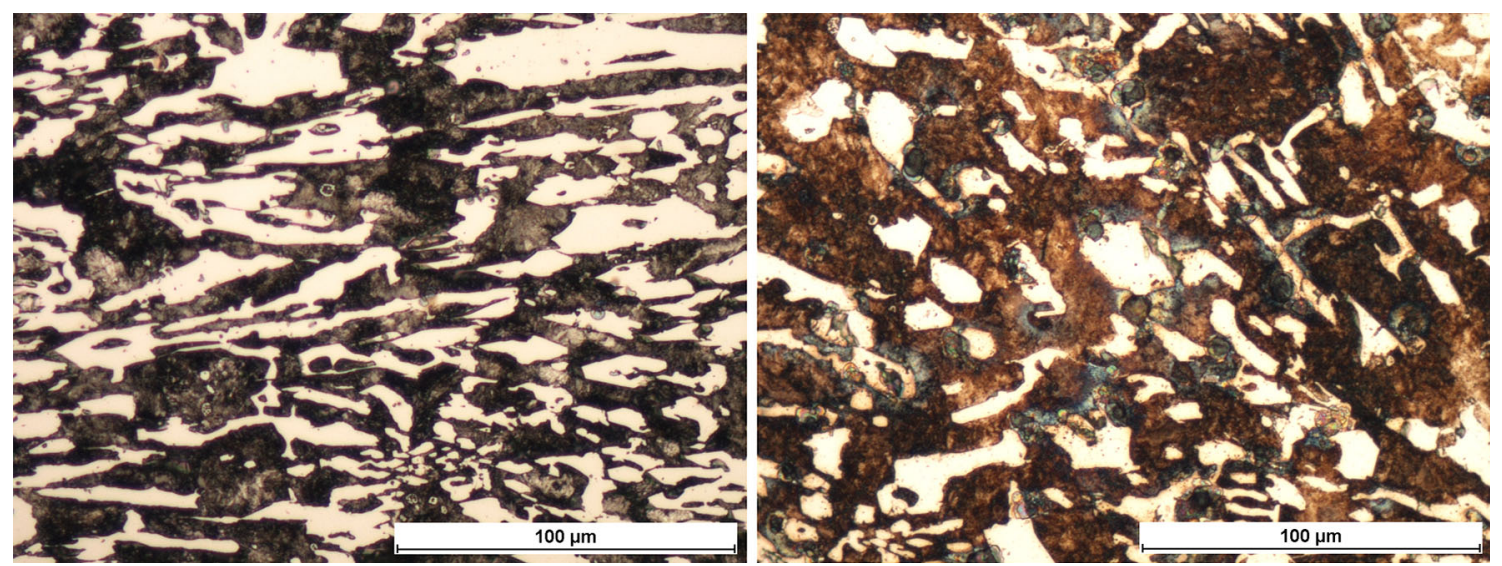

Fig. 7 Microstructure of TiMM004 sample, on the left ATD-C, on the right ATD-Is
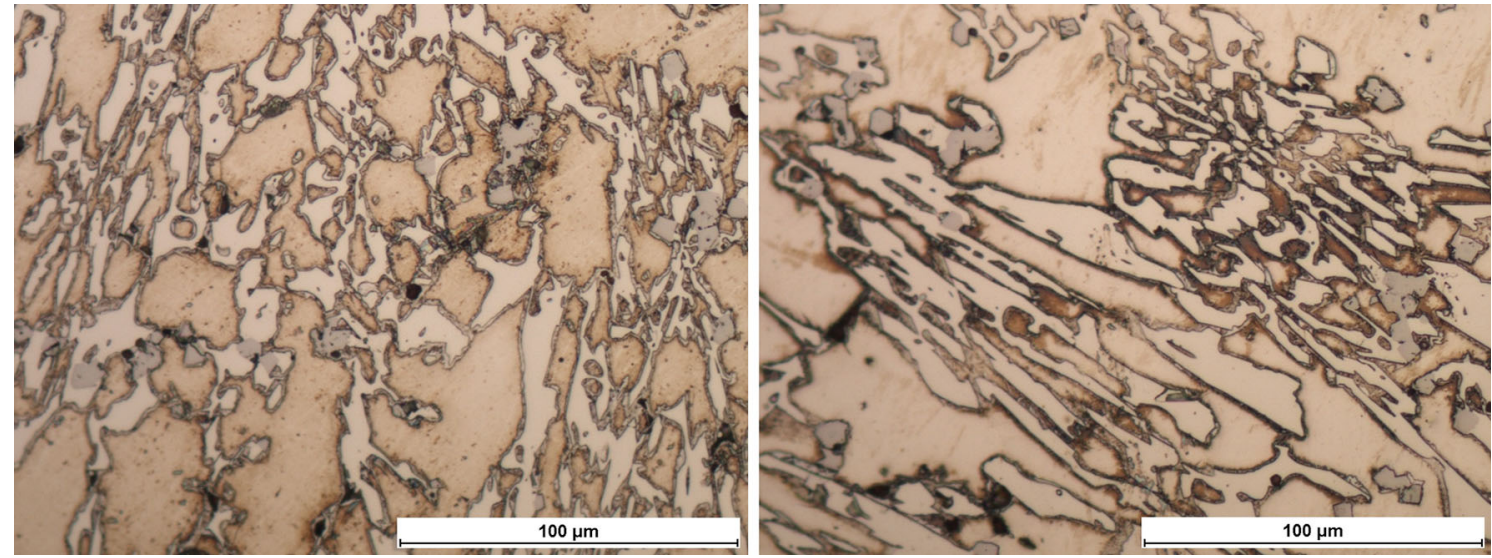

Fig. 8 Microstructure of TiMM1 sample, on the left ATD-C, on the right ATD-Is

of the examined samples compared to the wear resistance test reference sample Ref (C8).

When analyzing Fig. 9, it can be noticed that wear of W0 sample was $69 \%$ lower than the wear of C8 sample, while both inoculated samples presented better wear resistance than W0 and C8 samples. The best wear resistance in the examined conditions was achieved by TiMM1 sample. Wear of TiMM004 sample was $29 \%$ lower than the wear of W0 sample, and $71 \%$ lower than C8 sample, the wear of TiMM1 sample was $41 \%$ lower than the wear of W0 sample, and $76 \%$ lower than C8 sample, while the wear of TiMM1 sample was $17 \%$ lower than the wear of TiMM004 sample. Increase in wear resistance in inoculated samples can be linked with the presence of $\mathrm{TiC}$ which, because of its hardness, can decrease the wear as well as 


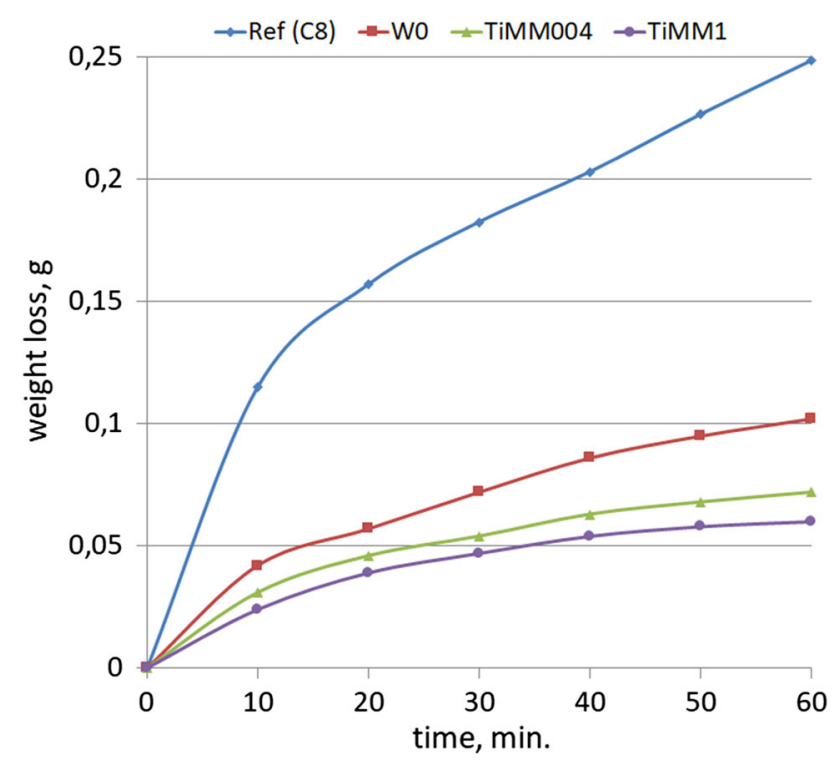

Fig. 9 Weight loss of the samples in wear measurement cycles

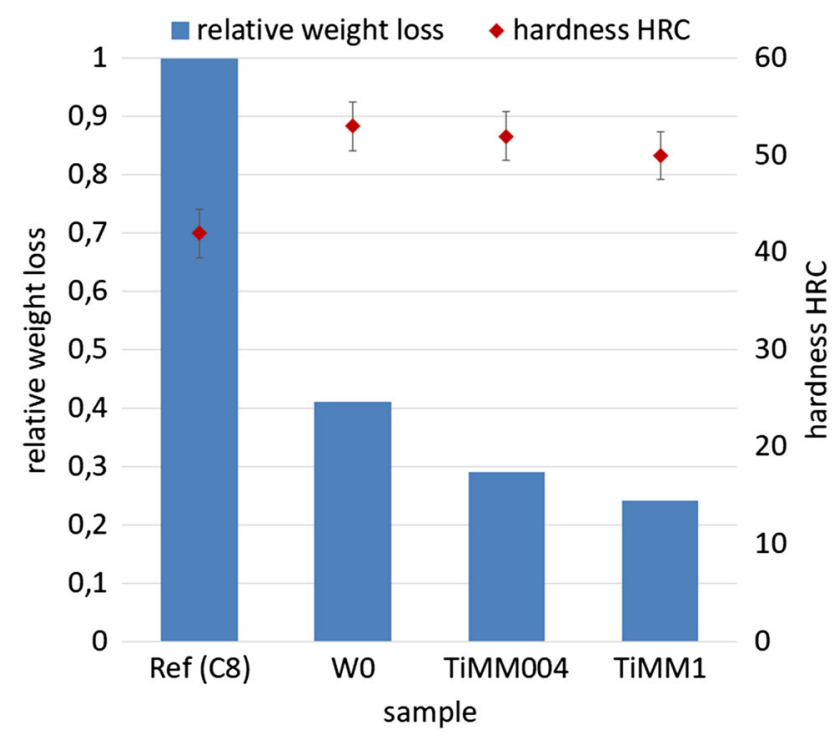

Fig. 10 Relative weight loss of examined samples in comparison with the wear test reference sample C8 and hardness HRC

the refinement of $\mathrm{Cr}_{7} \mathrm{C}_{3}$ which can decrease their chipping rate. The change in matrix from pearlite and austenite to pure austenite can result in enhanced plasticity of the matrix and increase in carbide support which also can reduce their chipping rate.

In comparison with authors previous research (Ref 1), in which W0 sample was contrasted with samples inoculated only with FeTi, weight loss of TiMM1 sample inoculated with combination of FeTi and REE was similar. However, in case of TiMM004, application of over three times less inoculant provided only slight (17\%) decrease in weight loss compared to other inoculated samples from both experiments. This may prove that from economical point of view mixture of FeTi and REE can be effective and attractive combination of inoculants to use in iron foundries.

\subsection{Hardness Analysis}

Samples used for the examination of wear resistance were subjected to hardness evaluation using Rockwell method. The results of the hardness test presented in Fig. 10 show the average value from six measuring points on each sample.

There is a known proportional relationship between hardness and wear resistance; however, hardness of each inoculated sample was lower in comparison with sample W0 (not inoculated one), which is the result of carbide phase refinement, as well as the change in the metal matrix of the alloy from pearlite to austenite. Similar effect of hardness reduction was obtained in other research (Ref 2) where inoculation was performed with only FeTi.

\subsection{SEM Analysis}

The EDS (energy-dispersive $\mathrm{x}$-ray spectroscopy) analysis was performed on Phenom Pro-X scanning electron microscope. This part of the study can show the influence of inoculants on crystallization process and microstructure of the analyzed chromium cast iron.

Figures 11 and 12 shows the element distribution map for TiMM1 sample, where it can be clearly seen that titanium carbides are adjacent to the eutectic carbides, which can translate into their ability to serve as an underlay for the crystallization of $\mathrm{Cr}_{7} \mathrm{C}_{3}$ carbides. The presence of $\mathrm{TiC}$ in such matter and the volume in eutectic precipitations can indicate that they are not only an inoculant of eutectic carbides, but constitute the eutectic itself.

Analysis of the map of a selected area of TiMM1 sample shows that the microstructure of alloy was determined by four elements- $\mathrm{Fe}, \mathrm{Cr}$, Ti, C; however, there are some light particles visible in the marked microstructure which were not detected by the analyzer. The chemical composition (in wt.\%) measured in the analyzed area is $64.6 \% \mathrm{Fe}, 18.6 \% \mathrm{Cr}, 9.6 \% \mathrm{Ti}$ and $7.2 \%$ C.

Particles with higher amount of $\mathrm{Ti}$ and $\mathrm{C}$ were identified as TiC particles. After execution of the linear analysis for those precipitations and light elements of the structure, the results presented in Fig. 13 were obtained.

High amounts of cerium and lanthanum can be observed on the light points, and close to those points, we can see $\mathrm{M}_{7} \mathrm{C}_{3}$ eutectic precipitations, along with $\mathrm{TiC}$, which means that $\mathrm{Ce}$ and $\mathrm{La}$ compound can be used as an effective underlay for $\mathrm{M}_{7} \mathrm{C}_{3}$ carbides, as well as an underlay for titanium carbide particles crystallization.

\section{Summary}

Eutectic recalescence was eliminated in both inoculated samples, which proves that effective inoculation took place. In TiMM04 sample, $T_{\mathrm{L}}, T_{\mathrm{S}}$ and $T_{\mathrm{H}}$ temperatures were higher compared to W0 sample, which could indicate higher crystallization start potential. In TiMM1 sample, in case of ATD-Is tester, $T_{\mathrm{L}}$ and $T_{\mathrm{H}}$ had increased compared to $\mathrm{W} 0$ melt, while $T_{\mathrm{S}}$ had decreased. In case of ATD-C tester, $T_{\mathrm{L}}, T_{\mathrm{S}}$ and $T_{\mathrm{H}}$ were lower than in W0 melt, which shows reduced crystallization start potential. In both inoculated samples, heat effects prior to $T_{\mathrm{L}}$ were present. In the authors' opinion, they can be related to $\mathrm{TiC}$ and $\mathrm{Ce}_{2} \mathrm{O}_{2} \mathrm{~S}$ precipitation. Further studies will be carried out to confirm this theory. 


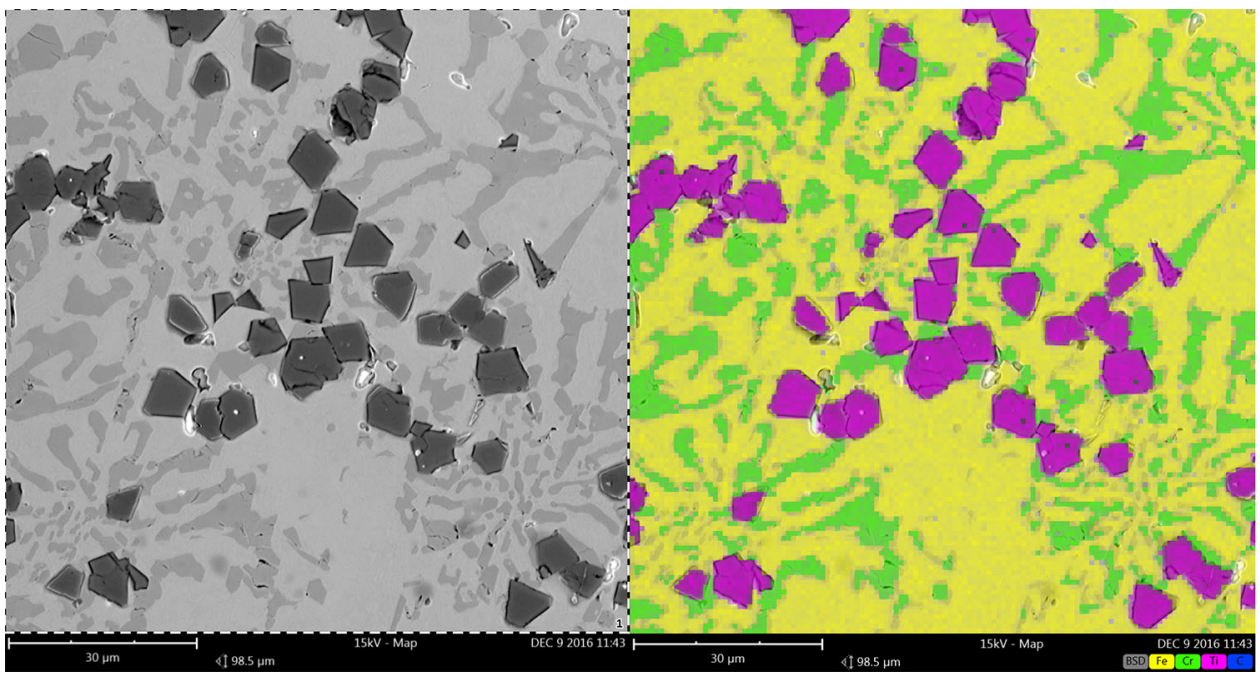

Fig. 11 Element distribution map for TiMM1 sample and SEM EDS scan

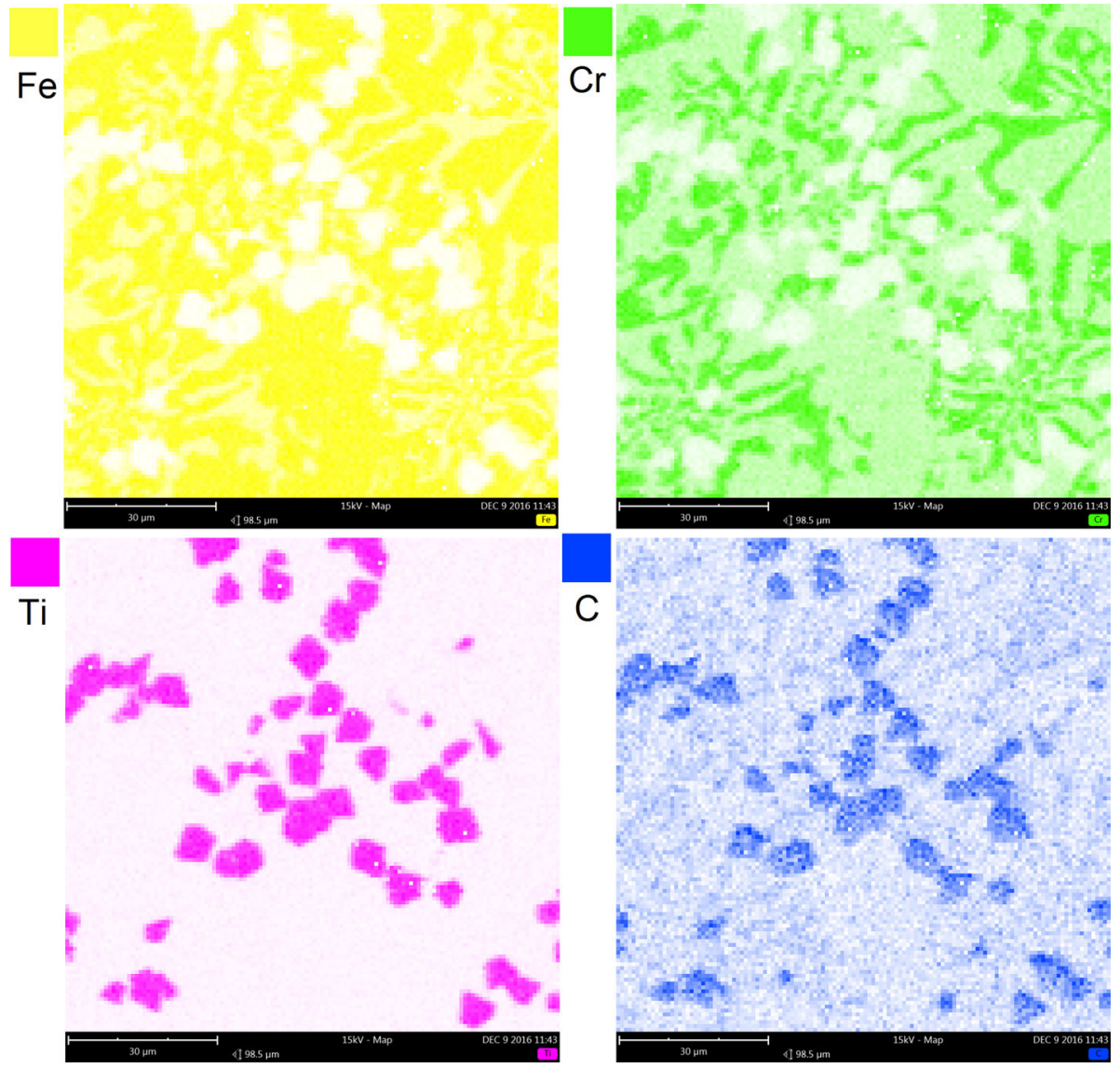

Fig. 12 Maps of individual element distribution for TiMM1 sample and SEM EDS scan

In TiMM004 and TiMM1 samples, the average carbide area and length had significantly decreased, while the rounding in inoculated samples was greater compared to the W0 sample. The analysis indicates that inoculation took effect, potentially increasing their impact strength. The transformation of the matrix from mixture of alloy pearlite and austenite to austenite in TiMM1 sample can be linked to a phenomenon where grain refinement decreases starting temperature of martensitic transition broadening stability of austenitic matrix to a room temperature. In TiMM1 samples, addition of a large amount of Ti resulted in formation of $\mathrm{TiC}$ conglomerates, as $\mathrm{TiC}$ was not evenly distributed in the matrix. Uneven distribution of $\mathrm{TiC}$ should be avoided, as it could contribute to increased wear in areas without $\mathrm{TiC}$, as well as it might cause cracks in areas with 

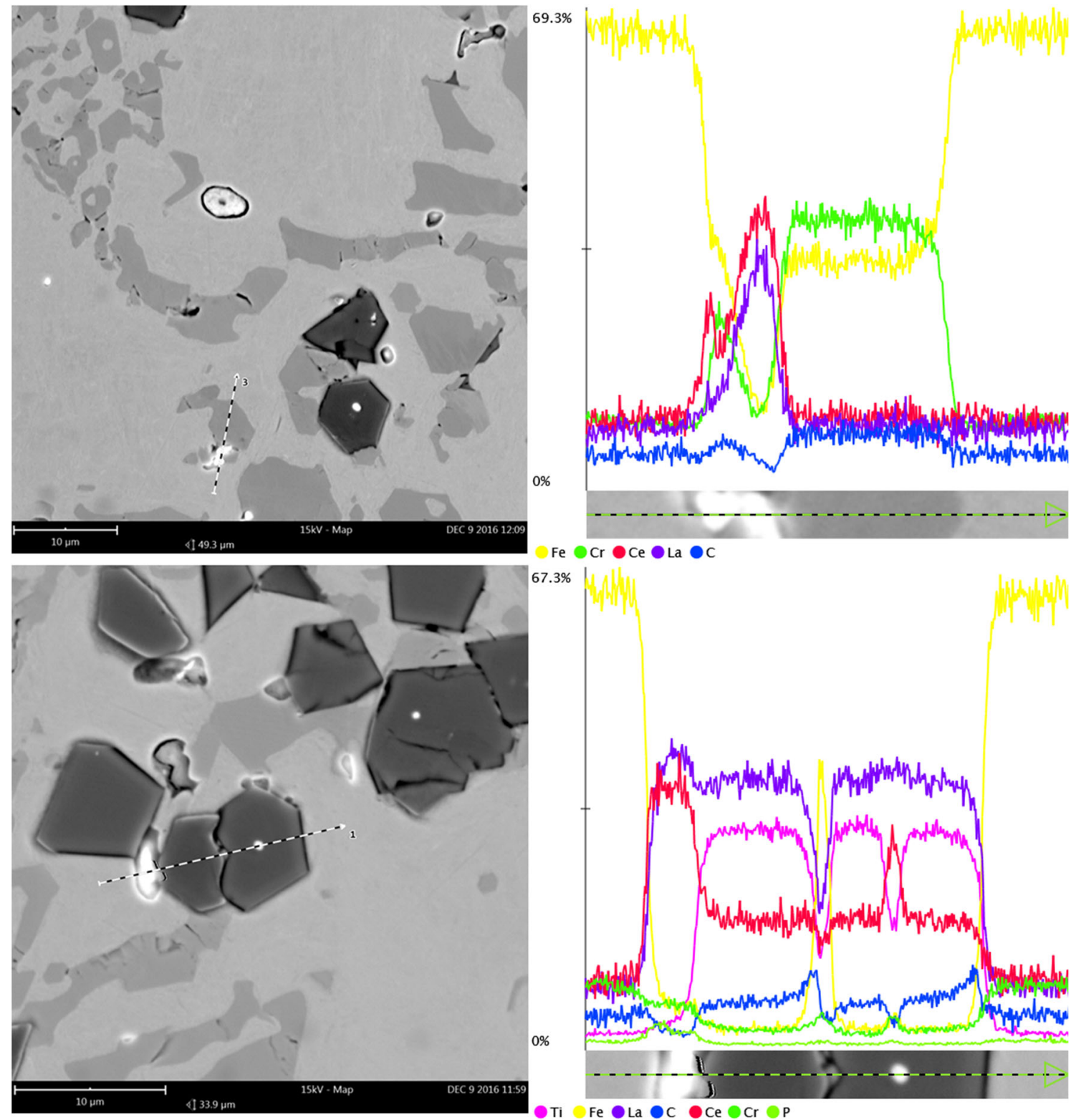

Fe $\bigcirc$ Cr O $\bullet$ La $\odot$

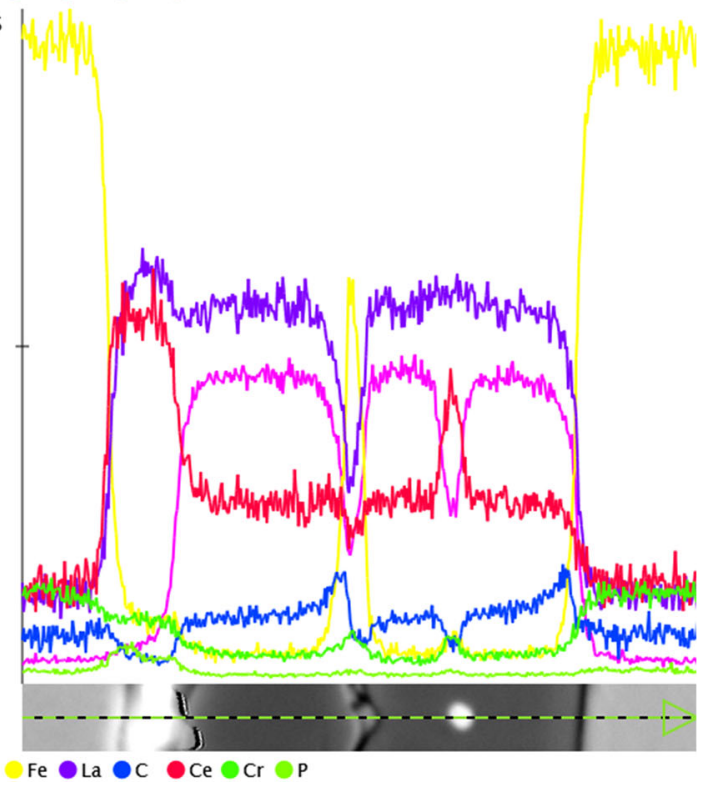

Fig. 13 Linear analysis of particles in TiMM1 sample and SEM EDS scan

conglomerates due to their high hardness. Addition of different inoculating elements, such as RE, should be promoted, because it allows to enhance properties of the alloy without creating additional conglomerated phases.

Inoculated samples were characterized by decreased hardness, compared to W0 sample, due to carbide refinement and change in matrix from alloy pearlite to austenite.

Inoculated samples presented better wear resistance than non-inoculated W0 sample. The best wear resistance was demonstrated by TiMM1 sample, as it was $17 \%$ better than TiMM004 sample. The important question is, whether achieving $17 \%$ less wear is worth using over three times more expensive alloying elements. For some applications, it may be, but the decision depends on various factors, which should be considered when planning the use of this material, because low manufacturing cost is a vital factor in case of high chromium cast iron.
In SEM analysis, we can observe that $\mathrm{TiC}, \mathrm{Ce}$ and $\mathrm{La}$ compounds are positioned adjacent to $\mathrm{Cr}_{7} \mathrm{C}_{3}$ carbides in TiMM004 and TiMM1 samples, which can indicate that both $\mathrm{TiC}$ and $\mathrm{Ce}_{2} \mathrm{O}_{2} \mathrm{~S}$ work as an effective nucleus for crystallization of $\mathrm{Cr}_{7} \mathrm{C}_{3}$ carbides. The research also showed that $\mathrm{Ce}_{2} \mathrm{O}_{2} \mathrm{~S}$ can work as a crystallization underlay for TiC. To substantiate that, it is necessary to conduct further studies including XRD analysis, image analysis and impact strength test.

\section{Open Access}

This article is distributed under the terms of the Creative Commons Attribution 4.0 International License (http://creativecommons.org/lice nses/by/4.0/), which permits unrestricted use, distribution, and reproduction in any medium, provided you give appropriate credit to the original author(s) and the source, provide a link to the Creative Commons license, and indicate if changes were made. 


\section{References}

1. A. Studnicki, R. Dojka, M. Gromczyk, and M. Kondracki, Influence of Titanium on Crystallization and Wear Resistance of High Chromium Cast Iron, Arch. Foundry Eng., 2016, 16(1), p 117-123

2. D. Kopyciński, E. Guzik, D. Siekaniec, and A. Szczęsny, The Effect of Addition of Titanium on The Structure and Properties of High Chromium Cast Iron, Arch. Foundry Eng., 2015, 15(3), p 35-38 (PAN, Katowice-Gliwice)

3. Y. Ma, X. Li, Y. Liu, S. Zhou, and X. Dang, Microstructure and Properties of Ti-Nb-V-Mo-Alloyed High Chromium Cast Iron, Bull. Mater. Sci., 2013, 36(5), p 839-844

4. Y. Ma, X. Li, Y. Liu, S. Zhou, and X. Dang, Effect of Ti-V-Nb-Mo Addition on Microstructure of High Chromium Cast Iron, China Foundry, 2012, 9(2), p 148-153

5. X. Zhi, J. Liu, J. Xing, and S. Ma, Effect of Cerium Modification on Microstructure and Properties of Hypereutectic High Chromium Cast Iron, Mater. Sci. Eng. A, 2014, 603, p 98-103

6. Y. Qu, J. Xing, X. Zhi, and JFuH Peng, Effect of Cerium on the AsCast Microstructure of a Hypereutectic High Chromium Cast Iron, Mater. Lett., 2008, 62(17-18), p 3024-3027

7. E. Guo, L. Wang, L. Wang, and Y. Huang, Effects of RE, V, Ti and B Composite Modification on the Microstructure and Properties of High Chromium Cast Iron Containing 3\% Molybdenum, Rare Met., 2009, 28(6), p 606-611

8. A. Bedolla-Jacuinde, S.L. Aguilar, and B. Hernández, Eutectic Modification in a Low-Chromium White Cast Iron by a Mixture of Titanium, Rare Earths, and Bismuth: I. Effect on Microstructure, $J$. Mater. Eng. Perform., 2005, 14(2), p 149-157

9. A. Bedolla-Jacuinde, S.L. Aguilar, and C. Maldonado, Eutectic Modification in a Low-Chromium White Cast Iron by a Mixture of Titanium, Rare Earths, and Bismuth: Part II. Effect on the Wear Behaviour, J. Mater. Eng. Perform., 2005, 14(3), p 301-306

10. K.G. Buchman, M.V. Kral, and C.M. Bishop, Crystallography and Morphology of MC Carbides in Niobium-Titanium Modified As-Cast HP Alloys, Metall. Mater. Trans. A, 2014, 45(8), p 3373-3385

11. H. Zhang, Q. Liu, H. Shibata, Q. Wang, P. Jonsson, J. He, and K. Nakajima, Partial Equilibrium Prediction of Solidification and Carbide Precipitation in Ti-added High Cr Cast Irons, ISIJ Int., 2014, 54(2), p 374-383

12. A. Bedolla-Jacuinde, R. Correa, J.G. Quezada, and C. Maldonado, Effect of Titanium on the As-Cast Microstructure of a $16 \%$ Chromium White Iron, Mater. Sci. Eng. A, 2005, 13(1-2), p 297-308

13. A. Bedolla-Jacuinde, R. Correa, I. Mejia, J.G. Quezada, and W.M. Rainforth, The Effect of Titanium on the Wear Behaviour of a $16 \% \mathrm{Cr}$ White Cast Iron Under Pure Sliding, Wear, 2007, 263(1-6), p 808-820
14. X. Wu, J. Xing, H. Fu, and X. Zhi, Effect of Titanium on the Morphology of Primary M7C3 Carbides in Hypereutectic High Chromium White Iron, Mater. Sci. Eng. A, 2006, 457, p 180-185

15. M. Dojka, R. Dojka, and A. Studnicki, Development of a New ATD-P Tester for Hard Wear Resistant Materials, Arch. Foundry Eng., 2017, 17(1), p $37-40$

16. M. Stawarz, M. Gromczyk, J. Jezierski, and K. Janerka, Analysis of the High Silicon Cast Iron Crystallization Process with TDA Method. in Metal 2015: 24th International Conference on Metallurgy and Materials (Ostrava), TANGER 2015, pp. 42-47

17. M. Dojka, R. Dojka, M. Kondracki, and A. Studnicki, Crystallization Process of High Chromium Cast Iron with the Addition of $\mathrm{Ti}$ and $\mathrm{Sr}$, Arch. Foundry Eng., 2018, 18(2), p 57-64

18. J. Gawroński, Profesor Stanisław Jura - twórca teorii zastosowań przemysłowych diagnostyki oraz zużycia metali i stopów [Professor Stanisław Jura the Creator of Theory and Industrial Application of Diagnostic and Wear of Metals and Alloys]. Arch. Foundry, 2004, 4(16) (in Polish)

19. S. Pietrowski, B. Pisarek, R. Władysiak, G. Gumienny, T. Szymczak, TDA Curves of the Metals Alloys and the Control of Their Quality, Postepy Teorii i Praktyki Odlewniczej, 1st ed., J. Szajnar, Ed., Komisja Odlewnictwa PAN, Poland, 2009, p 345-376

20. B. Borowiecki, Changeability Efficiency Metal Flow in Gating System with Function of Pour Times Summary, Arch. Foundry, 2004, 4(14), p 621-626 (in Polish)

21. R. Dojka and A. Studnicki, Influence of Boron on Crystallization and Microstructure of Ductile Cast Iron, Arch. Foundry Eng., 2017, 17(2), p $15-20$

22. R. Kuziak, K. Radwański, and A. Wrożyna, Role of the Advanced Microstructures Characterization in Modeling of Mechanical Properties of AHSS Steels, Mater. Sci. Eng. A, 2015, 639, p 567-574

23. A. Grajcar, R. Kuziak, and W. Zalecki, Third Generation of AHSS with Increased Fraction of Retained Austenite for the Automotive Industry, Arch. Civ. Mech. Eng., 2012, 12(3), p 334-341

24. D.K. Matlock and J.G. Speer, Third Generation of AHSS: Microstructure Design Concepts, Microstructure and Texture in Steels, A. Haldar, S. Suwas, D. Bhattacharjee, Eds., Springer, London, 2009, p 185-205

25. J. Campbell, Complete casting handbook. Metal Casting Processes, Metallurgy, Techniques and Design, 2nd ed., Oxford, ButterworthHeinemann, 2015

Publisher's Note Springer Nature remains neutral with regard to jurisdictional claims in published maps and institutional affiliations. 